\title{
Current Situation and Countermeasures of Learning Adaptability for College Filing Poor Students
}

\begin{abstract}
Liu Yan
International Business School, Shaanxi Normal University, Xi'an, Shaanxi 710119, China

Email: liuyan_snnu@163.com

ABSTRACT

In order to understand the current situation of learning adaptability of college filing poor students, this study forms a questionnaire after the appropriate deletion of the existing scale of learning adaptability of college students. Firstly, the questionnaire was tested in a small scale to verify the reliability, then the questionnaire was formally distributed to college filing poor students and ordinary college student. Then the recovery data are analyzed by SPSS17.0 software and IBM. SPSS. Amos. v21 software. The results show that there is no significant difference in learning motivation, teaching mode, learning ability and learning attitude between college filing poor students and ordinary college student, but environmental adaptability of college filing poor students is relatively weak; besides, the adaptability of female students to teaching mode is relatively strong. Based on the data analysis, this study puts forward some suggestions to improve the learning adaptability of college filing poor students.
\end{abstract}

Keywords: File establishment, learning adaptability, difference comparison

\section{INTROUDUCTION}

In November 2013, General Secretary Xi Jinping went to Hunan for inspecting and he put forward the thought of "targeted poverty alleviation" for the first time [1].In recent years, the importance of poverty alleviation by education in various colleges and universities has increased, and subsidies for poor students have been effectively carried out. However, the current assistance measures mainly meet the material needs of poor students, and there is room for improvement in the effective combination of financial assistance and the education of colleges and universities.

For college students, the process of receiving education at university is the process of accumulating human capital. In this process, the knowledge and skills they acquire will become a beneficial weapon for graduates to apply for a job or further study. As for college filing poor students, there are a lot of support measures in various colleges, but if the support measures for them are really implemented, they must pay attention to their university study status and the growth of human capital and increase its human capital content. Whether human capital is competitive depends largely on the learning situation, and learning adaptability can effectively assess the learning situation. The more adaptive the learning, the better the learning effect.

\subsection{Literature Review}

Many scholars at home and abroad have studied the main factors affecting learning adaptability. Foreign researchers have summarized the main factors affecting learning adaptability into two aspects: personality factors and environmental factors.

In terms of personality factors, Marti[2] discovers that academic self-efficacy, optimism and stress resistance are significantly positively correlated with college students' academic expectations and learning adaptability. In terms of environmental factors, there are many studies on the influence of family factors on college students 'learning adaptability and academic achievements; researchers mainly discuss the family upbringing methods, family structure, and socioeconomic status [3].These studies show that in the process of student socialization, parents play a very important role; whether students adapt to university life can be predicted by the relationship between students and parents. Besides, Campbell[4]also explores the learning adaptability of college students from the aspects of learner's gender, difficulty of learning tasks, school discipline norms, teaching interaction, dormitory environment, library materials and Internet information. About domestic study adaptability research, drawing on the American SLI theory, Xue Zhengbin puts forward effective suggestions for improving the learning adaptability of college students, mainly including improving the organization of college students' learning guidance and establishing a system for answering questions for teachers and students[5].Zhang Miao[6]studies the promotion methods of college students' learning adaptation in the field of "Internet + ", and puts forward suggestions that mainly include the transition from passive learning to innovative learning; from regulatory learning to customized learning. Zhao Chengling[ 7 ] discusses the influencing factors of college students' learning adaptability based on cyberspace learning. Liu Jiang[ 8 ]discusses the learning adaptability and its influencing factors of mainland students who study in Taiwan, government support and students' individual 
factors will affect their learning adaptability.

\subsection{Our Contribution}

At present, most studies on college students' learning adaptability focus on the overall study of college students, but there are few separate studies on college students' learning adaptability in different economic environments. There is even less research on the learning adaptability of poor students. This paper will make a comparative study on the learning adaptability of college filing poor students and ordinary college student and understand the weak points of college filing poor students ' learning adaptability. Based on the results of the comparative analysis, we put forward some suggestions to improve the learning adaptability of college filing poor students.

\subsection{Paper Structure}

The rest of the paper is organized as follows. Section 2 introduces research methodology, which include sample and procedure, measures. Section 3 introduces results, which include testing of validity and reliability, independent-samples T test. Finally, Section 4 concludes the paper and presents direction for future research.

\section{RESEARCH METHODOLOGY}

\subsection{Sample and Procedure}

In this study, college students of file establishment in Suiyang Guizhou were selected as the group of college filing poor students. The samples were distributed in the first year, second year, third year and fourth year respectively, and a similar number of samples were selected from each grade to make the samples more representative. ordinary college student came from a wide range of sources, and a total of 450 questionnaires were eventually issued. 430 questionnaires were collected, 416 were valid, and the effective rate was $97 \%$.

\subsection{Measures}

This study mainly refers to the scales with high reliability designed by Feng Tingyong, Li Hong[9].Based on this scale, the original scale was deleted for two reasons. First, in order to ensure the reliability of the data, the over-general problems are deleted. Second, in order to ensure the simplicity of the questionnaire, the two questions that express the same feature in the positive and negative directions are combined. Finally, 21 items are retained on the basis of 28 measured variables of the original scale.

\section{RESULTS}

\subsection{Testing of validity and reliability}

In this study, SPSS17.0 software was used to test the reliability of the questionnaire for the learning adaptability of college filing poor students through the Cronbach's alpha. The Cronbach's alpha of the general questionnaire in this study was 0.815 , and the Cronbach's alpha of each dimension of the scale were greater than 0.8 , and the questionnaire reliability was reliable.

In order to verify the reasonableness of the questionnaire structure, a confirmatory factor analysis was conducted on the five-factor model of learning adaptability. The combined reliability of the five latent variables were all between 0.75 and 0.89 , which had reached a standard greater than 0.7, indicating that the scale is internal Consistency is good. In order to test the discriminant validity of the scale, this study uses the average variation extraction method proposed by Fornell and Larker, and uses the square of the correlation coefficient between AVE and dimensions. The arithmetic square root of AVE is greater than the absolute value of the correlation coefficient, and the discrimination validity is good

\subsection{Independent-samples T test}

The final scale of the learning adaptability of college filing poor students consists of 19 measured variables, each of which is divided into a maximum of 5 points and a learning adaptability full score of 95 points. The number of students who college filing poor students 's learning adaptability score below 55 accounted for $16.7 \%$ of the total, and the number scored above 55 accounted for $83.3 \%$ of the total. It can be seen that the learning adaptability of the majority of college filing poor students is higher than the middle level. However, there are still some weak points that need to be further explored in various dimensions.

\subsubsection{A comparative analysis of the differences in factors of group learning adaptability}

In this study, an independent sample $\mathrm{T}$ test was used to compare the differences in learning adaptability between college filing poor students and ordinary college student from an overall perspective. The specific results are shown in table 1. 
Table 1 Learning adaptability difference table

\begin{tabular}{|c|c|c|c|c|c|c|}
\hline \multirow[t]{2}{*}{ Dimension } & \multicolumn{2}{|c|}{$\begin{array}{c}\text { College filing poor } \\
\text { students }\end{array}$} & \multicolumn{2}{|c|}{$\begin{array}{c}\text { Ordinary college } \\
\text { student }\end{array}$} & \multirow[t]{2}{*}{$\mathbf{T}$} & \multirow[t]{2}{*}{ Sig } \\
\hline & Mean & SD & Mean & SD & & \\
\hline Learning motivation & 3.36 & 0.86 & 3.38 & 0.88 & 0.30 & 0.76 \\
\hline Teaching model & 3.48 & 0.95 & 3.24 & 0.89 & 2.71 & $0.00 * * *$ \\
\hline Learning ability & 3.71 & 0.74 & 3.73 & 0.76 & 0.21 & 0.83 \\
\hline Learning attitude & 3.57 & 0.94 & 3.57 & 0.98 & 0.09 & 0.93 \\
\hline Environmental factor & 2.46 & 0.81 & 2.77 & 0.86 & 3.90 & $0.00 * * *$ \\
\hline
\end{tabular}

$* * \mathrm{P}<0.01$

In table 1 , there are significant differences in the teaching mode and environmental factors between college filing poor students and ordinary college student, but no significant differences in the remaining factors. college filing poor students have better adaptability to the teaching model than ordinary college student; the average scores of environmental factors for college filing poor students are lower than the adaptation of ordinary college student to the environment Ability is weaker than ordinary college student. The ability to adapt to environmental factors of college filing poor students needs to be improved, and the

\subsubsection{Different gender learning adaptability differences}

The independent sample $\mathrm{T}$ test was used to study the differences in the learning adaptability of male students and female students from college filing poor students and ordinary college student. The specific results are shown in Table 2 and Table 3 . education department should pay attention to them.

Table 2 Differences in learning adaptability among boys

\begin{tabular}{|c|c|c|c|c|c|c|}
\hline \multirow{2}{*}{ Dimension } & \multicolumn{2}{|c|}{$\begin{array}{c}\text { College filing poor } \\
\text { students }\end{array}$} & \multicolumn{2}{|c|}{$\begin{array}{c}\text { Ordinary college } \\
\text { student }\end{array}$} & \multirow{2}{*}{$\mathbf{T}$} & \multirow{2}{*}{ Sig } \\
\hline & Mean & SD & Mean & SD & & \\
\hline Learning motivation & 3.38 & 0.88 & 3.37 & 1.00 & 0.06 & 0.95 \\
\hline Teaching model & 3.38 & 0.98 & 3.32 & 0.95 & 0.43 & 0.66 \\
\hline Learning ability & 3.83 & 0.71 & 3.75 & 0.90 & 0.70 & 0.49 \\
\hline Learning attitude & 3.48 & 1.01 & 3.39 & 1.08 & 0.57 & 0.57 \\
\hline Environmental factor & 2.23 & 0.68 & 2.99 & 0.92 & 5.74 & $0.00 * * *$ \\
\hline
\end{tabular}

Table 3 Differences in learning adaptability among girls

\begin{tabular}{|l|c|c|c|c|c|c|}
\hline \multirow{2}{*}{\multicolumn{1}{|c|}{ Dimension }} & \multicolumn{2}{|c|}{$\begin{array}{c}\text { College filing poor } \\
\text { students }\end{array}$} & \multicolumn{2}{c|}{$\begin{array}{c}\text { Ordinary college } \\
\text { student }\end{array}$} & \multirow{2}{*}{ T } & \multirow{2}{*}{ Sig } \\
\cline { 2 - 6 } & Mean & SD & Mean & SD & & 0.27 \\
\hline Learning motivation & 3.43 & 0.82 & 3.23 & 1.03 & 1.10 & $0.00 * * *$ \\
\hline Teaching model & 3.59 & 0.90 & 3.20 & 0.86 & 3.43 & 0.41 \\
\hline Learning ability & 3.75 & 0.78 & 3.61 & 1.01 & 0.82 & 0.23 \\
\hline Learning attitude & 3.77 & 0.99 & 3.53 & 1.01 & 1.22 & $0.00 * * *$ \\
\hline Environmental factor & 2.30 & 0.79 & 2.83 & 0.95 & 3.05 & 0.05 \\
\hline
\end{tabular}


In Table 2, about boys, there are significant differences in environmental factors between college filing poor students and ordinary college students, and there is no difference in other factors. college filing poor students are less able to adapt to environmental factors than ordinary college students. The adaptability of college filing poor students need to be improved in environmental factors, and the education department should pay attention to it.

In Table 3, about girls, there are significant differences in the teaching mode and environmental factors between college filing poor students and ordinary college students, and there is no difference in other factors. The adaptability of college filing poor students to the teaching mode is stronger than ordinary college students; the environmental adaptability of college filing poor students is weaker than ordinary college students. To improve the learning adaptability of such college students should start from these aspects.

\section{CONCLUSION}

\section{1. main conclusion}

By analyzing learning adaptability of college filing poor students and comparing with ordinary college students, this study illustrates that college filing poor students' learning adaptability has reached above medium level, but the individual dimension still needs to be improved; its overall adaptability to the environment is weaker than that of ordinary college students; in terms of gender comparison, the adaptability of college filing poor students to boys is weaker than ordinary college students; the adaptability of teaching model is stronger than ordinary college students, but the adaptability to environmental factors is relatively weak.

\subsection{Practice suggestions}

At present, all colleges and universities pay more attention to college filing poor students. In order to improve the learning adaptability of these students and help them develop better, this article makes the following suggestions based on the results of comparative analysis:

(1) The education department provides professional guidance for the college entrance examination when filling in the application. Before providing guidance for their professional choices, the education department should conduct a census of professional employment rates, categorize the requirements and characteristics of students choosing different majors, and use brochures, lectures and other methods to guide the professional choices of college filing poor students, So that they can organically combine their hobbies and needs with professional choices.

(2) Increase funding and publicity efforts to reduce the financial burden of college filing poor students. Today's funding policy system is relatively complete. If college filing poor students apply accurately, they can generally solve most of the economic problems. Therefore, relevant departments should increase the propaganda of the subsidy policy to ensure that the policy really plays a role, and solve the worries about the establishment of college filing poor students.

(3) Improve university living conditions and create a good learning atmosphere. For college filing poor students, all activities to enter the university are carried out at the university. Maslow 's hierarchy of needs emphasizes that high-level satisfaction is required only when people 's low-level needs are met. Therefore, the school should meet the needs of college filing poor students as much as possible, and ensure its better learning.

(4) To help college filing poor students make good career plans and clarify their learning goals. Today's employment environment is relatively severe. In order to weaken the adverse impact of the employment environment on the learning of college filing poor students, the school should help college filing poor students make a good career plan. When carrying out this work, schools should pay attention to the development of career planning that needs to be close to the needs of the society and combine career planning with the personal characteristics of college filing poor students.

\subsection{Limitations and further research avenues}

Due to limited resources, the source of college filing poor students is relatively single, and due to the limitations of my communication circle, the number of samples is limited. The research perspective is mostly from the student's subjective perspective. In the future research on the current situation of learning adaptability of college filing poor students, it should not be limited to the perspective of subjective understanding, and add some objective indicators to the status of learning adaptability of college filing poor students, the measurement will be more accurate. Expanding the scope of the study and increasing the sample size make the study more general.

\section{REFERENCES}

[1] Tang, W.R. (2015) Interpretation of Jinping Xi 's thoughts on precise poverty alleviation [J]. People's Tribune, (30):28-30.

[2] Chemers, M.M.; Hu, L.T.; Garcia, B.F. (2001) Academic self-efficacy and first year college student performance and adjustment[J]. Journal of Educational Psychology, 93(1):55-64.

[3] Strage, A.A. (1998) Family context variables and the development of self-regulation in college students[J]. Adolescence, 33(129):17-31. 
[4] Campbell, M.H.; Prichard, S.T. (2000) Factor structure of the college adjustment scales[J]. Psychological Reports, 86(1):79-84.

[5] Xue, Z.B. (2016) The Implication of American SLI theory for the learning adaptability education for university students $[\mathrm{J}]$. Contemporary Education and Culture, 8(06): 80-84.

[6]Zhang, M. (2017) Research on the improvement path of college students' learning and adaptation ability in the "Internet +" field [J]. Contemporary Education Sciences, (04):93-96.

[7] Zhao, C.L; Wu, D.D; Jiang, Z.H; et al. (2019) Research on the influencing factors of college students' learning adaptability in the network learning space [J]. Open Education Research, (02):78-86.

[8]Liu, J. (2019) An analysis of the learning adaptability and influencing factors of the mainland students in Taiwan [J]. Taiwan Research Journal, (02):31-43.

[9] Feng, T.Y.; Su, T; Hu, X.W; et al. (2006) The development of a test about learning adjustment of undergraduate $[\mathrm{J}]$. Acta Psychologica Sinica, (05): 762-769. 